\title{
Intralanthanide Separation on Layered Titanium(IV) Organophosphate Materials via a Selective Transmetalation Process
}

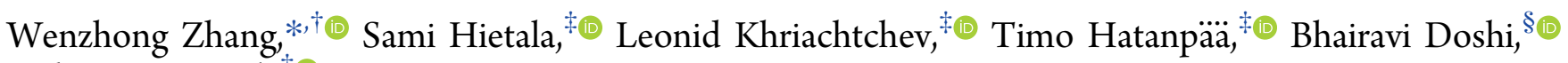 \\ and Risto Koivula ${ }^{\dagger}$ \\ ${ }^{\dagger}$ Department of Chemistry—Radiochemistry and ${ }^{\ddagger}$ Department of Chemistry, FI-00014 University of Helsinki, A. I. Virtasen Aukio \\ 1, P. O. Box 55, Helsinki, Finland \\ ${ }^{\S}$ Department of Green Chemistry, School of Engineering Science, Lappeenranta University of Technology, Sammonkatu 12, \\ FI-50130 Mikkeli, Finland
}

Supporting Information

ABSTRACT: The lanthanides ( $\mathrm{Ln})$ are an essential part of many advanced technologies. Our societal transformation toward renewable energy drives their ever-growing demand. The similar chemical properties of the Ln pose fundamental difficulties in separating them from each other, yet high purity elements are crucial for specific applications. Here, we propose an intralanthanide separation method utilizing a group of titanium(IV) butyl phosphate coordination polymers as solid-phase extractants. These materials are characterized, and they contain layered structures directed by the hydrophobic interaction of the alkyl chains. The selective Ln uptake results from the transmetalation reaction (framework metal cation exchange), where the titanium(IV) serves as sacrificial coordination centers. The "tetrad effect" is observed from a dilute $\mathrm{Ln}^{3+}$ mixture. However, smaller $\mathrm{Ln}^{3+}$ ions are preferentially extracted in competitive binary separation models between adjacent Ln pairs. The intralanthanide ion-exchange selectivity arises synergistically from the coordination and steric strain preferences, both of which follow the reversed Ln contraction order. A one-step aqueous separation of neodymium (Nd) and dysprosium (Dy) is quantitatively achievable by simply controlling the solution $\mathrm{pH}$ in a batch mode, translating into a separation factor of greater than 2000 and $99.1 \%$ molar purity of Dy in the solid phase. Coordination polymers provide a versatile platform for further exploring selective Ln separation processes via the transmetalation process.

KEYWORDS: titanium phosphate, ion exchange, lanthanide contraction, organophosphate ligand, solid-phase extraction

\section{INTRODUCTION}

The lanthanide $(\mathrm{Ln})$ series, collectively made up of a group of 15 elements, has gained strategic importance in recent decades. The unique $4 \mathrm{f}$ electron structures entail distinctive and, in many cases, irreplaceable physical properties that make Ln essential components in advanced electronics, lasers, and permanent magnets. ${ }^{1,2}$ Owing to the poor shielding of nuclear charge by $4 \mathrm{f}$ electrons, $\mathrm{Ln}^{3+}$ ions share extremely similar yet descending ionic radii across the series with an average difference between adjacent elements of only $1 \mathrm{pm}$ ( $\mathrm{Ln}$ contraction). ${ }^{3}$ Consequently, Ln forms isostructural mineral compounds that are almost always found together in the geosphere. ${ }^{4}$ Despite their considerably similar chemical characters, the magnetic and optical properties of Ln differ, and as a result, obtaining pure fractions of individual $\mathrm{Ln}$ is crucial for specific applications. The efficient separation of $\mathrm{Ln}$ remains a challenging task.

Historically, fraction crystallization was adopted to produce pure $\mathrm{Ln} .{ }^{5}$ This is proven to be tedious and time-consuming because hundreds of cycles are required. During the
Manhattan project, ion-exchange chromatography utilizing organic resins was developed to separate Ln and actinides. The difficulties in continuous operation and resin regeneration restricted its further scalability. Nowadays, continuous liquidliquid extraction (solvent extraction) is the state-of-the-art technology for Ln separation on an industrial scale. ${ }^{6}$ The separation is enabled by complex-forming extractants that selectively transfer the Ln ions from the aqueous to organic phases. Nevertheless, the inevitable liquid waste generation in the solvent extraction process has resulted in a search for more environmentally friendly separation methods. ${ }^{7}$

Recent advances in f-element coordination chemistry have reopened the window for selective crystallization, (bio)mineralization, and supramolecular self-assembly. ${ }^{8-14}$ The small difference in ionic radii can be amplified during the crystallization with desirable multidentate ligands, resulting in

Received: March 19, 2018

Accepted: June 12, 2018

Published: June 12, 2018 
Table 1. Formulae and Molecular Mass for TiP Materials

\begin{tabular}{clccc} 
& & \multicolumn{2}{c}{ inorganic-to-organic $\mathrm{P}$ ratio } & \\
\cline { 3 - 4 } sample & \multicolumn{1}{c}{ compound formulae } & in synthesis liquor & in obtained material & molecular mass $(\mathrm{g}$ mol \\
TiP_1:0 & $\mathrm{TiO}_{0.02}(\mathrm{OH})_{2.88}\left(\mathrm{HPO}_{4}\right)_{0.23}\left(\mathrm{H}_{2} \mathrm{PO}_{4}\right)_{0.62} \cdot 0.25 \mathrm{H}_{2} \mathrm{O}$ & $\infty$ & $\infty$ & 183.9 \\
TiP_3:1 & $\mathrm{TiO}_{0.43}(\mathrm{OH})_{1.84}\left(\mathrm{HPO}_{4}\right)_{0.32}\left(\mathrm{H}_{2} \mathrm{PO}_{4}\right)_{0.39}(\mathrm{DBP})_{0.27} \cdot 0.24 \mathrm{H}_{2} \mathrm{O}$ & 3 & 2.63 & 215.4 \\
TiP_1:1 & $\mathrm{TiO}_{0.99}(\mathrm{OH})_{0.55}\left(\mathrm{HPO}_{4}\right)_{0.24}\left(\mathrm{H}_{2} \mathrm{PO}_{4}\right)_{0.28}(\mathrm{DBP})_{0.71} \cdot 0.31 \mathrm{H}_{2} \mathrm{O}$ & 1 & 0.73 & 277.4 \\
TiP_1:3 & $\mathrm{TiO}_{1.05}(\mathrm{OH})_{0.13}\left(\mathrm{HPO}_{4}\right)_{0.22}\left(\mathrm{H}_{2} \mathrm{PO}_{4}\right)_{0.07}(\mathrm{DBP})_{1.26} \cdot 0.10 \mathrm{H}_{2} \mathrm{O}$ & 0.33 & 0.23 & 360.2 \\
TiP_0:1 & $\mathrm{TiO}_{1.06}(\mathrm{OH})_{0.01}\left(\mathrm{H}_{2} \mathrm{PO}_{4}\right)_{0.24}(\mathrm{DBP})_{1.63}$ & 0 & 0.15 & 429.3
\end{tabular}

metal-organic framework (MOF) materials with fine-tuned sizes, shapes, and crystal structures. ${ }^{15}$ Often, these processes are energy-intensive because they are carried out hydrothermally. Biomineralization is active under milder conditions, yet the stability and reusability of artificial peptides are not satisfactory. Another approach-solid-phase extraction-completely eliminates the organic phase in solvent extraction. Organic-inorganic hybrid materials utilizing an array of inorganic porous supports and organic functional ligands have been developed for selective Ln sorption. ${ }^{16-20}$ Recently, we have shown that titanium alkyl-phosphate functionalized mesoporous silica possesses solvating extraction capability. ${ }^{21}$ The surface alkyl chains linked to titanium phosphate moieties mimic the structure of tri- $n$-butyl phosphate (TBP) and hence form complexes with Ln nitrates. However, these materials seem not to be perfect candidates for intralanthanide separation because of the similar complex formation constants across the Ln series.

Inorganic ion exchangers, namely, metal(IV) phosphate materials, are used for selective metal separation and decontamination. ${ }^{17,22,23}$ Purely inorganic titanium ${ }^{24}$ and zirconium phosphate ${ }^{25}$ ( $\mathrm{TiP}$ and $\mathrm{ZrP}$ ) materials were studied for rare-earth separation via cation exchanges with the proton in the hydrogenphosphate groups. This reversible extraframework cation exchange reaction does not disrupt the building blocks of the material, and therefore the metal selectivity is primarily based on ion-sieve selection and phosphate coordination. Whereas inorganic phosphate offers limited Ln selectivity, simple organic phosphoric acids [e.g., di- $n$-butyl phosphoric acid (HDBP) ${ }^{26}$ and di(2-ethylhexyl)-phosphoric acid (DEHPA $)^{27,28}$ ] demonstrate more promising intralanthanide separation potentials. The ratio of the solubility product constants $\left(K_{\mathrm{sp}}\right)$ between $\mathrm{Dy}(\mathrm{DBP})_{3}$ and $\mathrm{Nd}(\mathrm{DBP})_{3}$ is reported to be more than 4000 (DBP is the deprotonated form of HDBP). ${ }^{26}$ Titanium(IV) forms insoluble, layer-structured precipitates with DBP in the form of a coordination polymer. ${ }^{29}$ The resultant material is composed of alternating bilayers of butyl chains and titanium(IV) phosphate. Although titanium(IV) and zirconium(IV) phosphonates were intensively studied, ${ }^{30,31}$ there has been extremely limited information regarding the properties and application of titanium(IV) organophosphate materials in metal separation.

In the present work, we describe the synthesis and characterization of layered titanium(IV) butyl phosphate materials and their uptake behavior toward $\mathrm{Ln}^{3+}$ ions. Contrary to what we observed from the surface alkyl-phosphate grafted materials, the titanium(IV) butyl phosphate materials do not retain $\mathrm{Ln}^{3+}$ in a solvating extraction manner. Instead, the driving force for $\mathrm{Ln}^{3+}$ uptake originates from transmetalation reactions [framework $\mathrm{Ti}(\mathrm{IV})$ exchange]. Significant group separation was achieved for early and late Ln. This observation forms the basis of a Ln separation strategy that combines both the high selectivity from the crystallization method and the operational convenience from solid-phase extraction.

\section{EXPERIMENTAL SECTION}

Chemicals. Titanium(IV) tetrachloride $\left(\mathrm{TiCl}_{4},>97 \%\right)$ and HDBP $(>97 \%)$ were purchased from Sigma-Aldrich. Lanthanide (including $\mathrm{La}, \mathrm{Ce}, \mathrm{Pr}, \mathrm{Nd}, \mathrm{Eu}, \mathrm{Gd}, \mathrm{Tb}, \mathrm{Dy}, \mathrm{Yb}$, and $\mathrm{Lu}$ ) solutions were prepared from their corresponding nitrate salts ( $>99.9 \%$, Sigma-Aldrich). orthoPhosphoric acid $(>99.9 \%)$ and ethanol $(>99.5 \%)$ were purchased from VWR Chemical. For metal (uptake) analysis, elemental standard solutions (1000 $\mathrm{mg} \mathrm{L}^{-1}$, PrimAg-plus cert. ref. material) and nitric acid (SpA super purity, 67-69\%) were obtained from ROMIL (Cambridge, UK). Ultrapure water (Milli-Q, Millipore) with a resistivity of $18.2 \mathrm{M} \Omega \mathrm{cm}$ was used.

Synthesis of the TiP Materials. A precipitation method was employed for the synthesis of the $\mathrm{TiP}$ materials. By carefully dissolving $\mathrm{TiCl}_{4}$ in water under vigorously stirring (1000 rpm, 1 h), a completely transparent $\mathrm{Ti}(\mathrm{IV})$ precursor solution (1 M) was obtained. A series of phosphate precursor solutions $(0.2 \mathrm{M}$ total $\mathrm{P})$ was prepared by diluting different amounts of $85 \% \mathrm{H}_{3} \mathrm{PO}_{4}$ and $\mathrm{HDBP}$ into a $50 / 50(\mathrm{v} / \mathrm{v})$ water/ethanol mixture, with the final $\mathrm{H}_{3} \mathrm{PO}_{4}$-toHDBP molar ratios at 1:0, 3:1, 1:1, 1:3, and 0:1. The precipitation reaction was carried out by the dropwise addition of $10 \mathrm{~mL}$ of the $\mathrm{Ti}(\mathrm{IV})$ precursor into $100 \mathrm{~mL}$ of the phosphate precursors while stirring $(1000 \mathrm{rpm})$. Note that the $\mathrm{P} / \mathrm{Ti}$ molar ratio in all synthesis liquors was fixed to 2 . The suspension was aged at room temperature for $1 \mathrm{~h}$ under the same stirring condition. The resulting white slurry was then washed three times with the water/ethanol mixture through centrifugation ( $2 \mathrm{~min}, 5000 \mathrm{~g}$ ) and redispersion. Finally, the materials obtained were air-dried at $60{ }^{\circ} \mathrm{C}$ in an oven overnight. The materials synthesized from the phosphate precursors with different inorganicto-organic phosphate ratios were denoted as TiP $x / y$, where $x / y=$ $n\left(\mathrm{H}_{3} \mathrm{PO}_{4}\right) / n(\mathrm{DBP})=1: 0,3: 1,1: 1,1: 3$, and 0:1 (Täble 1). All of them were ground and sieved to a particle size between 74 and $149 \mu \mathrm{m}$ (100-200 mesh) before further study.

X-ray Diffraction. The powder X-ray diffraction (XRD) patterns in the Bragg-Brentano geometry were recorded by a PANalytical X'Pert3 PW3710 MPD diffractometer control unit, a PW3020 vertical goniometer, and a monochromatic $\mathrm{Cu} \mathrm{K} \alpha$ radiation source $(\lambda=$ $1.54056 \AA$ ) operated at $40 \mathrm{kV}$ and $40 \mathrm{~mA}$.

Infrared Spectroscopy. Infrared (IR) spectra $\left(650-4000 \mathrm{~cm}^{-1}\right)$ were recorded on a PerkinElmer Spectrum One Fourier transform infrared (FTIR) spectrometer equipped with a Universal attenuated total reflection (ATR) sampling accessory.

Raman Spectroscopy. Raman spectra were recorded using a confocal Raman microscope (NTEGRA Spectra, NT-MDT) in the 100 -to- $1200 \mathrm{~cm}^{-1}$ region with a spectral resolution of $2 \mathrm{~cm}^{-1}$. The measurements were performed with a $532 \mathrm{~nm} \mathrm{Nd:YAG} \mathrm{laser} \mathrm{(output}$ power $20 \mathrm{~mW}$ ) and a $100 \times$ objective. The acquisition time was typically $1 \mathrm{~min}$. We checked that the laser light did not damage the sample.

Surface Area. The Brunauer-Emmett-Teller (BET) surface area and porosity of the materials were determined at $77 \mathrm{~K}$ by the nitrogen $\left(\mathrm{N}_{2}\right)$ adsorption-desorption method (TriStar II Plus, Micromeritics), and the samples were degassed at $150{ }^{\circ} \mathrm{C}$ for $5 \mathrm{~h}$ prior to the measurements (VacPrep 061 degassing unit).

Scanning Electron Microscopy. The surface morphology of the TiPs was observed using a Hitachi S-4800 FE-SEM (field-emission 

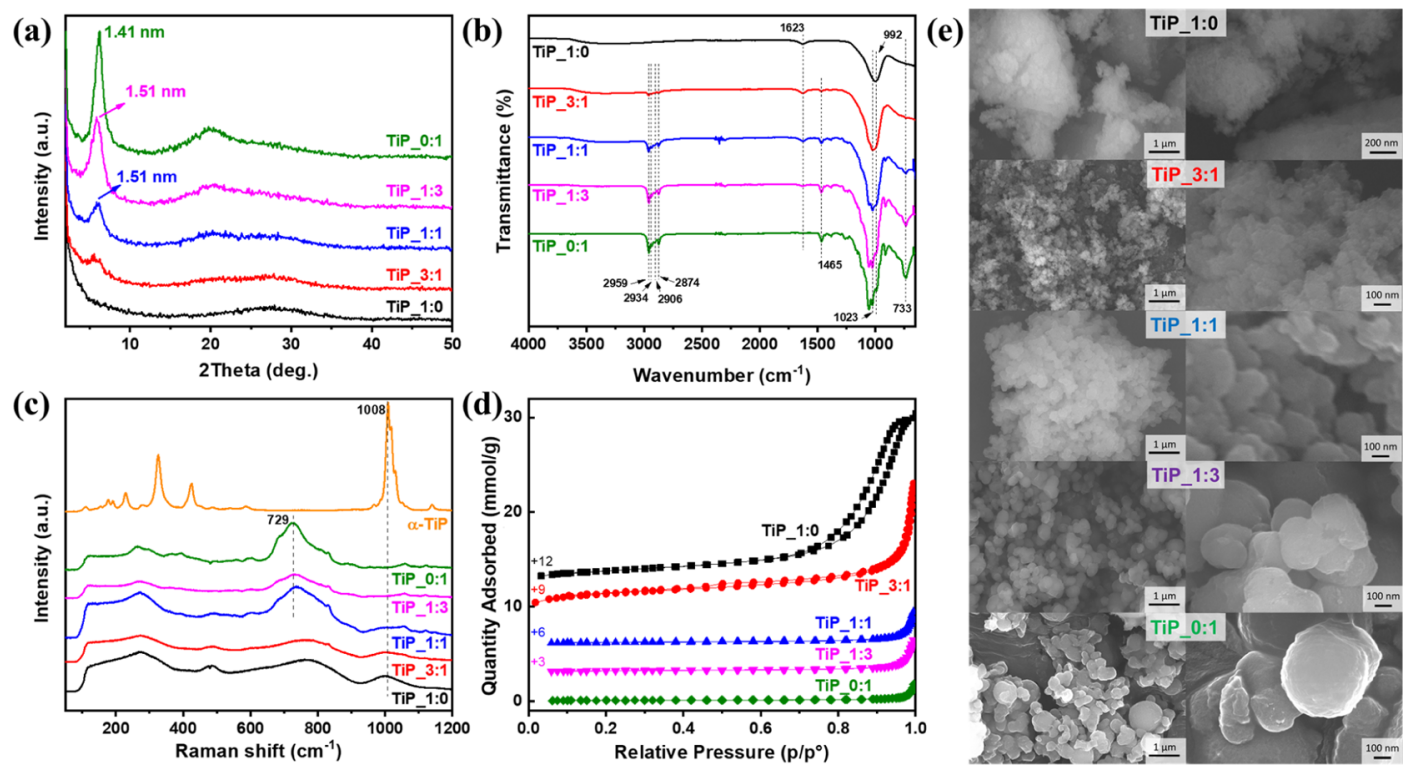
Figure 1. Characterizations of the synthesized TiP materials. (a) Powder XRD patterns. (b) ATR-FTIR spectra. (c) Raman spectra with
crystalline $\alpha$-TiP as a comparison. (d) Nitrogen adsorption-desorption isotherms measured at $77 \mathrm{~K}$. (e) SEM images (smaller magnification in the left column and higher magnification in the right column).

scanning electron microscopy) after they were sputter-coated with a 3 nm layer of $\mathrm{Pd}-\mathrm{Au}$ alloy.

Compositional Analysis. The elemental contents (C and $\mathrm{H}$ ) were analyzed using a Thermo Scientific Flash 2000 elemental analyzer. The contents of Ti and P were determined by a PerkinElmer Optima 8300 inductively coupled plasma optical emission spectrometer (ICP-OES) after total digestion in $65 \% \mathrm{HNO}_{3}$ and $1 \% \mathrm{HF}$ using a CEM MARS 5 microwave digestion system.

Thermogravimetry. The simultaneous thermogravimetry and differential scanning calorimetry-mass spectroscopy (TG/DSC-MS) analysis was performed using a simultaneous TG/DSC apparatus (STA 449F3 Jupiter, Netzsch) connected to a JAS-Agilent GC-MS (7890B GC/MSD5977A). In the dynamic TG measurements, the samples were heated from 30 to $800{ }^{\circ} \mathrm{C}$ at a heating rate of $20{ }^{\circ} \mathrm{C}$

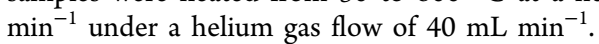

Solid-State Nuclear Magnetic Resonance. The solid-state ${ }^{13} \mathrm{C}$ and ${ }^{31} \mathrm{P}$ magic-angle spinning (MAS) nuclear magnetic resonance (NMR) spectra were collected on a Bruker AVANCE III $500 \mathrm{MHz}$ spectrometer equipped with a $4 \mathrm{~mm} \mathrm{H} / \mathrm{X} / \mathrm{Y}$ MAS probe. The samples were filled in a $4 \mathrm{~mm}$ zirconia rotor and measured at a MAS rate of 12 $\mathrm{kHz} .{ }^{13} \mathrm{C}$ spectra were recorded with ${ }^{1} \mathrm{H}-{ }^{13} \mathrm{C}$ cross-polarization (CP) pulse sequence, 2048 scans, a recycle delay of 5 s, spinal- $64{ }^{1} \mathrm{H}$ decoupling, and a contact time $0.5 \mathrm{~ms}$. The spectra were referenced with respect to adamantane at $38.5 \mathrm{ppm} .{ }^{31} \mathrm{P}$ spectra were acquired with a $90^{\circ}$ pulse $(77 \mathrm{kHz}$ rf), a $100 \mathrm{~s}$ recycle delay, and 64 scans. The ${ }^{31} \mathrm{P}$ chemical shifts were referred to external $85 \% \mathrm{H}_{3} \mathrm{PO}_{4}$ at $0 \mathrm{ppm}$.

Metal Concentration Determination. Determination of the metals was performed on an Agilent microwave plasma-atomic emission spectrometer 4200. Depending on suitability, one of Sc, La, or Fe was used as the internal standard for quality control. Samples were diluted to concentrations below $25 \mathrm{mg} \mathrm{L}^{-1}$, and a linear calibration curve was established by $0,0.5,1,2,5,10$, and $25 \mathrm{mg} \mathrm{L}^{-1}$ standard solutions.

$\mathrm{Ln}^{3+}$ Uptake Study. The $\mathrm{Ln}^{3+}$ ion-exchange extraction was studied in a batch mode. Typically, $50 \pm 1 \mathrm{mg}$ of TiP material was placed in a polyethylene vial with $10 \mathrm{~mL}$ of $\mathrm{Ln}^{3+}$-containing solution. Samples were equilibrated for $48 \mathrm{~h}$ (unless otherwise stated) by constant rotary mixing $(50 \mathrm{rpm})$. The solid/liquid separation was then achieved by filtering through a $0.22 \mu \mathrm{m}$ poly(vinylidene difluoride) syringe filter, and the clear solution was pipetted for concentration determination. Equilibrium $\mathrm{pH}$ was measured from the remaining filtrate.
The distribution coefficient $\left(K_{\mathrm{d}}, \mathrm{mL} \mathrm{g}^{-1}\right)$ demonstrates the distribution of a $\mathrm{Ln}$ element (or a group of selected Ln elements) between the solution and the solid material. It was calculated by eq 1 :

$$
K_{\mathrm{d}}=\frac{\left[\overline{\operatorname{Ln}^{3+}}\right]_{\mathrm{t}}}{\left[\mathrm{Ln}^{3+}\right]_{\mathrm{t}}}=\frac{\left[\mathrm{Ln}^{3+}\right]_{\mathrm{i}}-\left[\operatorname{Ln}^{3+}\right]_{\mathrm{t}}}{\left[\operatorname{Ln}^{3+}\right]_{\mathrm{t}}} \times \frac{V}{m}
$$

where $\left[\overline{\mathrm{Ln}^{3+}}\right]_{\mathrm{t}}$ is the $\mathrm{Ln}^{3+}$ concentration in the solid $\left(\mathrm{mg} \mathrm{g}^{-1}\right)$ after the sorption, $\left[\mathrm{Ln}^{3+}\right]_{\mathrm{i}}$ and $\left[\mathrm{Ln}^{3+}\right]_{\mathrm{t}}$ are, respectively, the $\mathrm{Ln}^{3+}$ concentration of the solution before and after sorption $\left(\mathrm{mg} \mathrm{L}^{-1}\right)$, respectively, $V$ is the volume of the solution $(10 \mathrm{~mL})$, and $m$ is the mass of the material (0.05 g).

The separation factor (SF) between two $\mathrm{Ln}^{3+}$ ions or two groups of $\mathrm{Ln}^{3+}$ ions $\left(\mathrm{Ln}_{1}\right.$ and $\left.\mathrm{Ln}_{2}\right)$ was subsequently calculated based on their $K_{\mathrm{d}}$ values (eq 2):

$$
\mathrm{SF}_{\mathrm{Ln}_{1} / \mathrm{Ln}_{2}}=\frac{K_{\mathrm{d}}\left(\operatorname{Ln}_{1}\right)}{K_{\mathrm{d}}\left(\operatorname{Ln}_{2}\right)}
$$

\section{RESULTS AND DISCUSSION}

Synthesis and Characterization of the TiP Materials. $\mathrm{TiCl}_{4}$ is prone to hydrolysis even in acid media, and the stable species of titanium in our synthesis liquor is $\mathrm{TiO}^{2+}$ (eq 3 ), according to the Pourbaix diagram. ${ }^{32}$

$$
\mathrm{TiCl}_{4}+\mathrm{H}_{2} \mathrm{O} \rightarrow \mathrm{TiO}^{2+}+2 \mathrm{H}^{+}+4 \mathrm{Cl}^{-}
$$

The $\mathrm{TiO}^{2+}$ cations are then polymerized to form $(\mathrm{TiO})_{n}{ }^{2 n+}$ chains. Two kinds of phosphate precursors were employed in the synthesis, inorganic ortho-phosphoric acid $\left(\mathrm{H}_{3} \mathrm{PO}_{4}\right)$ and organic HDBP. Pure inorganic TiPs are a group of $-\mathrm{H}_{2} \mathrm{PO}_{4}$ and/or $-\mathrm{HPO}_{4}$ containing proton-type ion exchangers, which have been extensively studied. ${ }^{33}$ The addition of HDBP to the synthesis liquor introduced the butyl phosphate functional groups onto the amorphous TiP assembly based on the inorganic backbone $(\mathrm{Ti}-\mathrm{O}-\mathrm{P})$ by condensation reactions. In our work, among the TiP materials synthesized (Table 1), TiP_1:0 is a purely inorganic material, whereas TiP_0:1 should supposedly contain only DBP groups. The others are categorized into organic-inorganic mixed TiPs. 
Inorganic TiP 1:0 exhibited a typical amorphous phase with a broad low-intensity powder XRD peak (Figure 1a). The addition of HDBP resulted in the evolution of a peak at $2 \theta=$ $5.9-6.3^{\circ}$, which translates into an interlayer spacing of $1.41-$ $1.51 \mathrm{~nm}$. This observation corresponds with an earlier study and suggests that these materials contain self-assembled butyl group layers stacked via van der Waals interactions. ${ }^{29}$ Despite the layered structure, the material lacks long-range periodic order. This is mainly due to the high reactivity of $\mathrm{Ti}(\mathrm{IV})$, leading to the formation of octahedral Ti-oxo-clusters and consequently amorphous coordination polymers. The high charge and polarizing power of $\mathrm{Ti}(\mathrm{IV})$ contribute to the chemical stability of the coordination polymer. ${ }^{34}$ A similar situation applies to $\mathrm{Zr}(\mathrm{IV})$. $^{31}$

The ATR-FTIR peaks (Figure 1b) centered at 2959, 2934, 2906 , and $2874 \mathrm{~cm}^{-1}$ are assigned to the stretching vibration of $\mathrm{C}-\mathrm{H}$ in butyl groups. The $1465 \mathrm{~cm}^{-1}$ band represents the deformation vibration of the same groups. ${ }^{29}$ The IR absorptions at 1023 and $733 \mathrm{~cm}^{-1}$ are typical vibrational modes for $\mathrm{C}-\mathrm{O}-(\mathrm{P})$ in phase vibration and $\mathrm{P}-\mathrm{O}_{3}$ symmetrical stretching, respectively. ${ }^{35}$ The water content characterized by the $\mathrm{O}-\mathrm{H}$ vibration at $1623 \mathrm{~cm}^{-1}$ becomes less evident with the increased organic content, as the hydrophobicity increases. The Raman spectra (Figure 1c) revealed additional information regarding the linkage between tetrahedral $\mathrm{PO}_{4}$ and octahedral $\mathrm{TiO}_{6}$ groups. The broad peaks at about $730 \mathrm{~cm}^{-1}$ in TiP $0: 1$, TiP $1: 3$, and TiP $1: 1$ materials are assigned to the vibration of $\mathrm{Ti}-\mathrm{O}-\mathrm{Ti}$ chains that contain nonbridging oxygen. ${ }^{36-38}$ This peak moves toward higher Raman shifts and becomes less evident in TiP_3:1 and TiP_1:0 samples, and it is completely absent in crystalline $\alpha$ TiP. We therefore infer that the heterocondensation between $\mathrm{Ti}-\mathrm{O}-\mathrm{H}$ and $\mathrm{P}-\mathrm{O}-\mathrm{H}$ groups competes with the homocondensation process for $\mathrm{Ti}-\mathrm{O}-\mathrm{H}$ during the synthesis. HDBP possesses only one $\mathrm{P}-\mathrm{O}-\mathrm{H}$ group, whereas $\mathrm{H}_{3} \mathrm{PO}_{4}$ harbors three. Because we fixed the overall $\mathrm{P} / \mathrm{Ti}$ molar ratio at 2 , the homocondensation reaction is expected to be more evident in the synthesis precursor with a higher amount of HDBP. In general, the Raman spectra of the TiPs exhibit an amorphous nature without any sharp peaks. The stretching vibrations of the isolated phosphate groups (in the $1000 \mathrm{~cm}^{-1}$ region) are only observable from TiPs with a higher inorganic phosphate content (TiP_1:0 and TiP_3:1).

$\mathrm{N}_{2}$ porosimetry analysis showed that the TiP samples have different textural characteristics, as summarized in Table 2. For the organic-containing TiP materials except TiP_3:1, the $\mathrm{N}_{2}$ adsorption-desorption isotherms (Figure 1d) are type II with very small hysteresis of type $\mathrm{H} 3$, suggesting monolayer-

Table 2. Textural Parameters of the Synthesized TiPs

$\begin{array}{ccccc}\text { sample } & S_{\text {BET }}\left(\mathrm{m}^{2} \mathrm{~g}^{-1}\right)^{a} & V_{\text {total }}\left(\mathrm{cm}^{3} \mathrm{~g}^{-1}\right)^{b} & D_{\text {pore }}(\mathrm{nm})^{c} & D_{\text {particle }}(\mathrm{nm})^{d} \\ \text { TiP_1:0 } & 142 & 0.62 & 15.1 & 42.3 \\ \text { TiP_3:1 } & 184 & 0.43 & 14.6 & 32.7 \\ \text { TiP_1:1 } & 16.0 & 0.12 & 38.7 & 375.0 \\ \text { TiP_1:3 } & 6.5 & 0.05 & 40.0 & 916.6 \\ \text { TiP_0:1 } & 1.2 & 0.01 & 72.0 & 5168.2\end{array}$

${ }^{a} S_{\mathrm{BET}}$ : BET surface area. ${ }^{b} V_{\text {total }}:$ total pore volume estimated from the desorption branch by the Barrett-Joyner-Halenda (BJH) method. ${ }^{c} D_{\text {pore }}$ : average pore diameter estimated from the desorption branch by the BJH method. ${ }^{d} D_{\text {particle }}$ : average particle size calculated by density functional theory. multilayer adsorption and aggregation of particles in these TiP materials. However, TiP_3:1 and purely inorganic TiP_1:0 sample gave a type $\operatorname{IV}(\mathrm{a})$ isotherm with a hysteresis in the $\bar{p} / p_{0}$ range of $0.45-1.0$ and $0.7-1.0$, respectively, ${ }^{39}$ which is associated with capillary condensation taking place in their respective mesopores. In $\mathrm{TiP}$ 1:0, the hysteresis loop is $\mathrm{H} 2$ (b), associated with pore blocking, with larger size distribution of the next widths, whereas in TiP 3:1, the change in hysteresis to type $\mathrm{H} 3$, due to aggregation of particles. The addition of small amount of organophosphate (in TiP_3:1) increased the surface area and decreased the average particle size (Table 2). As a general trend, the BET surface area decreases drastically with the synthetic addition of organophosphate. The TiP_0:1 sample has a strikingly low surface area $\left(1.2 \mathrm{~m}^{2} \mathrm{~g}^{-1}\right)$, whereas the inorganic amorphous TiP_1:0 sample presents a contrasting value of $142 \mathrm{~m}^{2} \mathrm{~g}^{-1}$. The selfassembly of the butyl groups into a lamellar format resulted in lower pore volume, larger average pore diameter, and significant growth (aggregation) of the particles. This is consistent with the morphological observation by SEM images in Figure 1e. These TiP materials appear as irregular pellets that are connected to each other. It is worth noting that the inorganic TiP_1:0 sample exhibits irregularly shaped large lumps under microscopic observation. The addition of small amount of organophosphate (in TiP_3:1) increased the surface area and decreased the average particle size. The capillary condensation of $\mathrm{N}_{2}$ shifts to lower relative pressure from the TiP_3:1 to TiP_0:1 sample, reflecting a decrease in the pore volume due to the introduction of organophosphate. The structural and morphological design of the inorganic TiP materials would be beneficial when small amounts of organophosphate are added as structural modifiers. Nevertheless, this is not the target of the current work and would require further and detailed investigation.

In order to solve the formulae of the obtained TiP materials, an array of supplementary characterizations was made. The carbon $(\mathrm{C})$, hydrogen $(\mathrm{H})$, titanium $(\mathrm{Ti})$, and phosphorus $(\mathrm{P})$ contents were determined by elemental analysis (EA) and total digestion. The thermogravimetric analysis (TGA) (Figure 2a) weight loss at below $105{ }^{\circ} \mathrm{C}$ gave an estimate of the adsorbed water contents (0-3\%, Table 3). Solid-state ${ }^{13} \mathrm{C}$ CP MAS NMR (Figure 2b) was run to check that all of the $\mathrm{C}$ was sourced from the organic DBP groups and there was no residual solvent. In addition, solid-state ${ }^{31} \mathrm{P}$ MAS NMR with peak deconvolutions (Figure $2 \mathrm{c}$ ) provided us the relative ratios between the $-\mathrm{H}_{2} \mathrm{PO}_{4}$ and $-\mathrm{HPO}_{4}$ groups. It is reported that peaks with a ${ }^{31} \mathrm{P}$ chemical shift at -5 to $-9 \mathrm{ppm}$ result from $-\mathrm{H}_{2} \mathrm{PO}_{4}$ groups, whereas those at -15 to $-22 \mathrm{ppm}$ represent $-\mathrm{HPO}_{4}$ groups. ${ }^{38}$ Peaks close to $1-2 \mathrm{ppm}$ are assigned to DBP based on our liquid NMR results. The detailed peak positions and relative quantification of the inorganic phosphate groups are present in Table 3. Although the synthesis precursor for TiP 0:1 consisted only of HDBP, inorganic $-\mathrm{H}_{2} \mathrm{PO}_{4}$ groups were found in the final TiP $0: 1$. For this, a partial hydrolysis of HDBP in acid media would be a logical explanation.

To gain more insights into the composition of the TiP materials, they were calcined at $800{ }^{\circ} \mathrm{C}$ under atmospheric condition for $6 \mathrm{~h}$. The resulting white powders were characterized by SEM (Figure $\mathrm{S} 1$ in the Supporting Information), XRD, and Raman spectroscopy. The calcined TiP materials are composed of titanium pyrophosphates (Figure 2d), including $\mathrm{TiP}_{2} \mathrm{O}_{7}$ and $(\mathrm{TiO})_{2} \mathrm{P}_{2} \mathrm{O}_{7}$ (ICDD card 

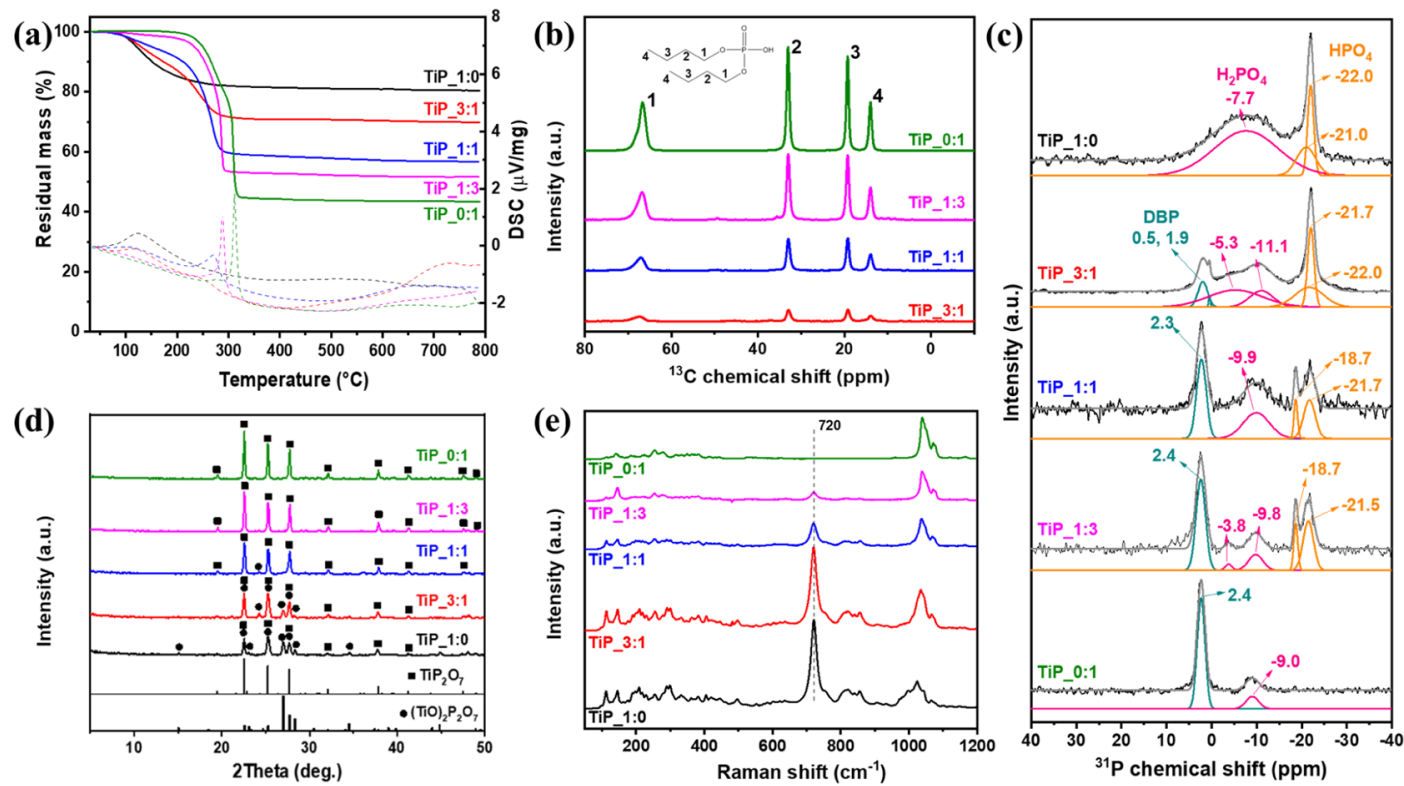

Figure 2. Characterizations in relation to formulae calculations. (a) TG curves (solid line and left $y$-axis) and DSC curves (dashed line and right $y$ axis). (b) ${ }^{13} \mathrm{C}$ CP MAS NMR spectra. (c) ${ }^{31} \mathrm{P}$ MAS NMR spectra with peak deconvolutions. (d) Powder XRD patterns of the calcined TiP materials compared with ICDD reference patterns. (e) Raman spectra of the calcined TiP materials.

Table 3. Characterization Results Used for the Formulae Calculations

\begin{tabular}{|c|c|c|c|c|c|c|c|c|c|c|c|}
\hline \multirow[b]{3}{*}{ material } & & & & & \multicolumn{4}{|c|}{${ }^{31} \mathrm{P}$ NMR peak fitting } & \multicolumn{3}{|c|}{ TGA } \\
\hline & \multicolumn{2}{|c|}{ EA } & \multicolumn{2}{|c|}{ digestion } & \multicolumn{2}{|c|}{$\mathrm{HPO}_{4}$} & \multicolumn{2}{|c|}{$\mathrm{H}_{2} \mathrm{PO}_{4}$} & \multirow{2}{*}{$\begin{array}{l}\text { DBP } \\
\text { ppm }\end{array}$} & \multicolumn{2}{|c|}{ mass loss $\%$} \\
\hline & C wt \% & H wt $\%$ & P wt \% & Ti wt \% & ppm & $\%$ & ppm & $\%$ & & $105{ }^{\circ} \mathrm{C}$ & $800{ }^{\circ} \mathrm{C}$ \\
\hline TiP_1:0 & 0.1 & 2.8 & 15.1 & 27.5 & $-22.0,-21.0$ & 27.6 & -7.7 & 72.4 & & 2.6 & 19.6 \\
\hline TiP 3:1 & 12.7 & 4.2 & 15.2 & 24.0 & $-22.0,-21.7$ & 45.2 & $-5.3,-11.1$ & 54.8 & $0.5,1.9$ & 2.2 & 30.1 \\
\hline TiP_1:1 & 24.5 & 5.4 & 13.8 & 17.3 & $-21.7,-18.7$ & 46.4 & -9.9 & 53.6 & 2.3 & 2.0 & 43.3 \\
\hline TiP_1:3 & 33.8 & 6.5 & 13.3 & 13.2 & $-21.5,-18.7$ & 72.2 & $-3.8,-9.8$ & 27.8 & 2.4 & 0.5 & 48.3 \\
\hline TiP_0:1 & 39.0 & 7.5 & 14.2 & 11.9 & & & -9 & 100 & 2.3 & 0.0 & 56.6 \\
\hline
\end{tabular}

numbers 00-038-1468 and 00-039-0207, respectively). The XRD peaks of these two pyrophosphates overlap to some extent; nevertheless, we were able to distinguish them using Raman spectroscopy. The peak at $720 \mathrm{~cm}^{-1}$ (Figure 2e) signifies the presence of $\mathrm{Ti}-\mathrm{O}-\mathrm{Ti}$ chains that contain nonbridging oxygen, as we discussed earlier. Therefore, only $(\mathrm{TiO})_{2} \mathrm{P}_{2} \mathrm{O}_{7}$ can produce Raman scattering at $720 \mathrm{~cm}^{-1}$. A small amount of amorphous $\mathrm{TiO}_{2}$ is believed to be present in all calcined samples because of the oxygen-rich calcination environment. Amorphous $\mathrm{TiO}_{2}$ is a weak Raman scatterer and thus cannot be fully characterized with this technique. ${ }^{40}$

On the basis of all aforementioned characterizations, we were able to determine the composition of the samples. The calculated formulae are listed in Table 1. The detailed calculations and justifications are provided as the Supporting Information. For the TiP materials synthesized from mixed organic-inorganic precursors, the inorganic-to-organic $\mathrm{P}$ ratios in the obtained materials are lower than that in the synthesis liquor. Substantially higher $\mathrm{Ti}(\mathrm{IV})$ reactivity was observed for HDBP than for $\mathrm{H}_{3} \mathrm{PO}_{4}$. The obtained titanium(IV) butyl phosphate materials contain hydroxyl and oxy groups. The increased oxy anion content from the TiP_1:0 to TiP_0:1 series confirmed the results from Raman spectroscopy. Solvent extraction of $\mathrm{Ti}(\mathrm{IV})$ by DEHPA yields the extractable $\left[\mathrm{TiO}(\mathrm{DEHPA})_{2}\right]$ complex, where deprotonated DEHPA acts as a bidentate ligand to occupy the vacant coordination sites of the $(\mathrm{TiO})_{n}{ }^{2 n+}$ chains. $^{41,42}$ The TiP_0:1 material is believed to have a similar structure (Scheme 1 ).

Scheme 1. Proposed Structure of the TiP_0:1 Material Showing the Layered Assembly and the Local Coordination of $\mathrm{Ti}(\mathrm{IV})$

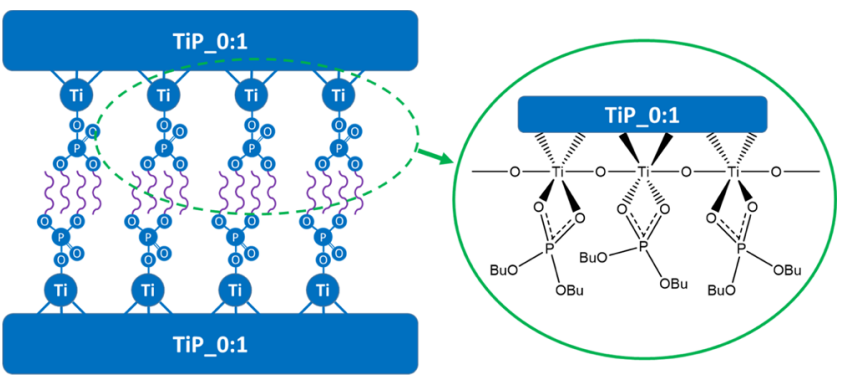

Preliminary Investigation of Ln Uptake Capability. The separation between early and late $\mathrm{Ln}^{3+}$ ions serves as a reasonable indicator of the intralanthanide separation capability of the TiP materials. Therefore, preliminary batch trials on competitive $\mathrm{Nd}-\mathrm{Dy}$ uptake were conducted. The $\mathrm{Nd}-\mathrm{Dy}$ pair was chosen also because of its industrial relevance with respect to the recycling of $\mathrm{NdFeB}$ magnets. In all cases, the total $\mathrm{Ln}^{3+}$ uptake increased with the elevated equilibrium $\mathrm{pH}$ (Figure S2a) and there were no significant differences in the 
total uptake amounts between the TiP 0:1 and TiP 1:0 samples. However, the $\mathrm{SF}(\mathrm{Dy} / \mathrm{Nd})$ values for the $\mathrm{TiP}_{-}^{-} 1: 0$ sample stayed between 1 and 2 over the studied $\mathrm{pH}$ range $(1-$ 3 ), whereas the same values for $\mathrm{TiP}_{-} 0: 1$ increased with $\mathrm{pH}$ to more than 100 at approximately $\mathrm{pH}^{-} 2.8$ (Figure $\mathrm{S} 2 \mathrm{~b}$ ). In the hybrid TiP materials (TiP 1:3, TiP 1:1, and TiP 3:1), the $\mathrm{SF}(\mathrm{Dy} / \mathrm{Nd})$ maxima were observed in the $\mathrm{pH}$ range of $2.2-$ 2.6. The increase of $\mathrm{Nd}^{3+}$ uptake after this $\mathrm{pH}$ range was responsible for the subsequent decrease in $\mathrm{SF}(\mathrm{Dy} / \mathrm{Nd})$. The results of the preliminary investigation indicated that TiP_0:1 exhibited the best intralanthanide separation potential. Using the purely inorganic $\mathrm{TiP}_{3} 1: 0$ as a comparison, the selective uptake of the heavier $\mathrm{Ln}^{\overline{3+}}$ by TiP $0: 1$ should originate from the effect of the organophosphate functional groups. Therefore, the TiP_0:1 material, prepared from a purely organophosphate precursor, was selected for further separation and mechanism study in the current work. The hybrid TiPs would find applications when the selectivity requirements are not that high or when total $\mathrm{Ln}$ uptake is needed.

Proposed $\mathrm{Ln}^{3+}$ Uptake Mechanism and Kinetics. $\mathrm{Ln}^{3+}$ forms nitrate complexes in aqueous solutions. TBP is a solvating organophosphate extractant that coordinates to neutral $\mathrm{Ln}(\mathrm{NO})_{3}$ complexes (eq 4):

$$
\mathrm{Ln}^{3+}+3 \mathrm{NO}_{3}^{-}+3 \mathrm{TBP} \leftrightarrow\left[\mathrm{Ln}\left(\mathrm{NO}_{3}\right)_{3} \mathrm{TBP}_{3}\right]
$$

Previously, we reported a group of titanium(IV) alkylphosphate grafted silica materials that retain $\mathrm{Ln}^{3+}$ in a solvating extraction manner. ${ }^{21}$ The addition of nitrate salts significantly enhanced the uptake of $\mathrm{Nd}^{3+}$ and $\mathrm{Dy}^{3+}$ on these grafted materials, thereby suggesting that the uptake mechanism follows eq 4. However, the addition of $5 \mathrm{M} \mathrm{NH}_{4} \mathrm{NO}_{3}$ inhibited the $\mathrm{Ln}^{3+}$ uptake on the TiP_0:1 material (Figure S3). To elucidate the uptake mechanism, we closely monitored the $\mathrm{Ln}^{3+}$ uptake kinetics in two sorption systems.

The first proposed sorption system I consisted of $2 \mathrm{mM} \mathrm{Lu}^{3+}$ at an initial $\mathrm{pH}$ of 1.8. The uptake of $\mathrm{Lu}^{3+}$ appeared to be relatively slow, reaching less than $30 \%$ of the equilibrium uptake after $24 \mathrm{~h}$ of mixing (Figure 3a). Notably, significant amounts of $\mathrm{Ti}$ (soluble $\mathrm{Ti}(\mathrm{IV})$ ions irrespective of speciation) were dissolved into the solution during the first $24 \mathrm{~h}$. The shape of the $\mathrm{Ti}$ dissolution amount curve in Figure 3a resembles that of the solution $\mathrm{pH}$ changes in Figure $3 \mathrm{~b}$. The $\mathrm{Lu}^{3+}$ uptake could, therefore, result from the transmetalation reaction: metal cation exchange with framework $\mathrm{TiO}^{2+}$, according to eq 5. Here, the barred ions refer to the solid phase.

$$
3 \overline{\mathrm{TiO}^{2+}}+2 \mathrm{Ln}^{3+} \leftrightarrow 2 \overline{\mathrm{Ln}^{3+}}+3 \mathrm{TiO}^{2+}
$$

The ratio of dissolved $\mathrm{Ti}$ to $\mathrm{Lu}^{3+}$ uptake $\left[n(\mathrm{Ti}) / n\left(\mathrm{Lu}^{3+}\right)\right]$ was calculated and is presented in Figure $3 c$. The $n(\mathrm{Ti}) /$ $n\left(\mathrm{Lu}^{3+}\right)$ values are always below the theoretical value at 1.5 (according to eq 5) because of the rapid precipitation reaction of $\mathrm{TiO}^{2+}$ (eq 6), leading to the decrease in the amount of dissolved $\mathrm{Ti}$, the solution $\mathrm{pH}$, and the $n(\mathrm{Ti}) / n\left(\mathrm{Lu}^{3+}\right)$ value.

$$
\mathrm{TiO}^{2+}+n \mathrm{H}_{2} \mathrm{O} \leftrightarrow \mathrm{TiO}(\mathrm{OH})_{n}^{(2-n)+}+n \mathrm{H}^{+}
$$

The second proposed sorption system II involved competitive $\mathrm{Nd}^{3+}$ and $\mathrm{Dy}^{3+}$ uptake at an initial $\mathrm{pH}$ of 3.6. Over the course of $20 \mathrm{~d}$, the uptake of $\mathrm{Nd}^{3+}$ remained negligible $\left(<1 \mathrm{mg} \mathrm{g}^{-1}\right)$ while more than $97 \%$ of $\mathrm{Dy}^{3+}$ was removed from the solution (Figure 4a). Although the dissolved $\mathrm{Ti}$ concentrations were consistently lower than the detection

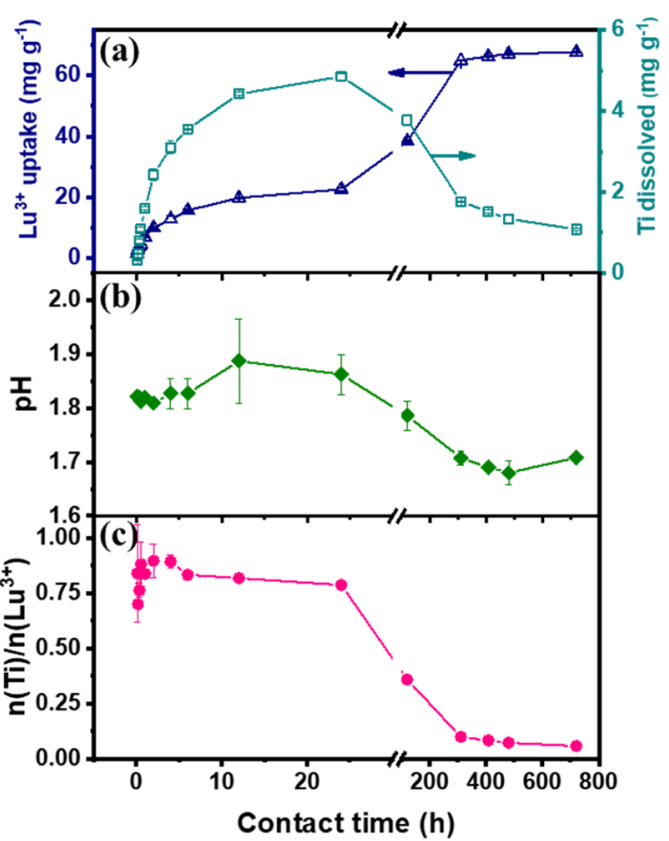

Figure 3. $\mathrm{Lu}^{3+}$ uptake kinetics on the TiP_0:1 material $\left(2 \mathrm{mM} \mathrm{Lu}^{3+}\right)$. Effect of contact time on (a) $\mathrm{Lu}^{3+}$ uptake and $\mathrm{Ti}$ dissolution, (b) solution $\mathrm{pH}$, and (c) $n(\mathrm{Ti}) / n\left(\mathrm{Lu}^{3+}\right)$ ratio.

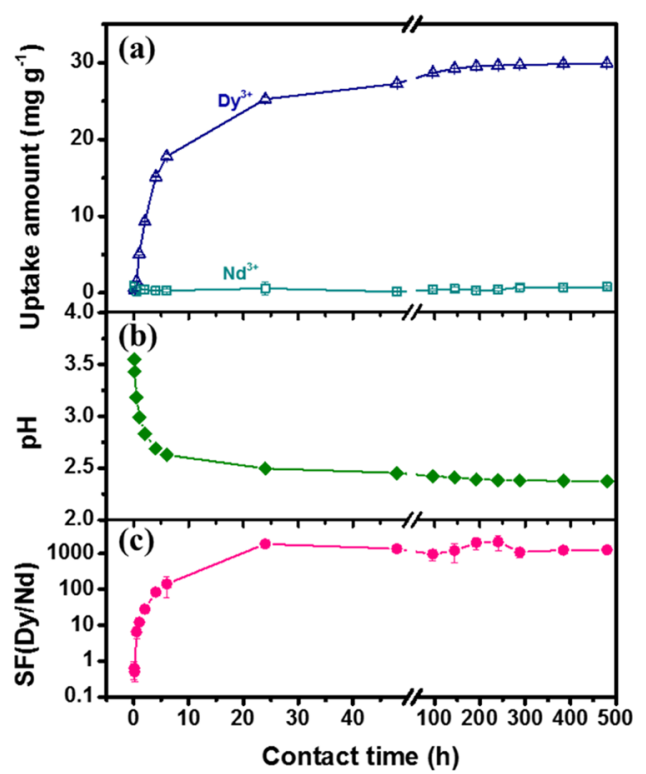

Figure 4. Competitive $\mathrm{Nd}^{3+}$ and $\mathrm{Dy}^{3+}$ uptake kinetics on the TiP_0:1 material $\left(1 \mathrm{mM}\right.$ equimolar mixture of $\mathrm{Nd}^{3+}$ and $\left.\mathrm{Dy}^{3+}\right)$. Effect of contact time on (a) $\mathrm{Nd}^{3+}$ and $\mathrm{Dy}^{3+}$ uptake, (b) solution $\mathrm{pH}$, and (c) $\mathrm{SF}(\mathrm{Dy} / \mathrm{Nd})$.

limit $\left(<10 \mu \mathrm{g} \mathrm{L}^{-1}\right)$, the drastic drop in the solution $\mathrm{pH}$ through the initial $10 \mathrm{~h}$ of contact (Figure $4 \mathrm{~b}$ ) indicated the ionexchange dissolution and rapid hydrolysis of $\mathrm{TiO}^{2+}$ (faster reaction rate for eq 5 at higher $\mathrm{pH}$ ). The calculated SFs $[\mathrm{SF}(\mathrm{Dy} / \mathrm{Nd})]$ reached over $10^{3}$ after $24 \mathrm{~h}$.

The sorption systems I and II were described by common kinetic models, and the detailed results are given in the Supporting Information (Figure S4). On the basis of the obtained high correlation coefficients $\left(R^{2}\right.$ close to 1$)$ and the closeness of the modeled equilibrium uptakes compared with the experimental values, both of the kinetics in systems I and II 
Scheme 2. Proposed Transmetalation Reaction on the TiP_0:1 Material Demonstrating the Exchange of Framework TiO ${ }^{2+}$ with $\mathrm{Dy}^{3+}$

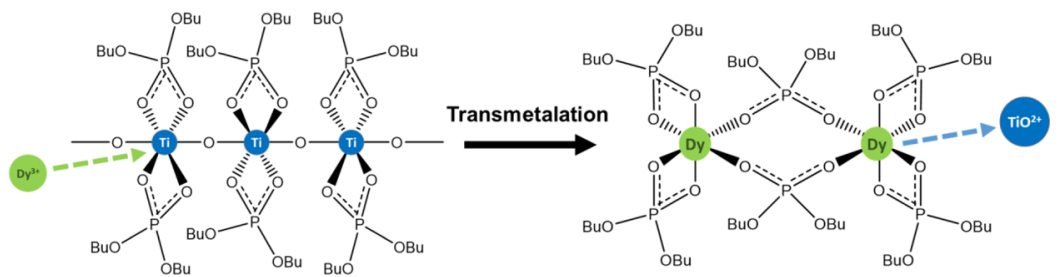

seem to obey the pseudo-second-order model (Table S2). However, further model validation suggested that the errors are not normally distributed and certain points have an unreasonably higher level of influence with a Cook's distance close to 0.5 (Figure S5-S6). The models especially failed to fit the uptake kinetics during the initial $24 \mathrm{~h}$ of contact (Figure S7). For system I, the initial accumulation of $\mathrm{Ti}^{4+}$ in the solution inhibited the equilibrium in eq 4 from shifting to the right side. For system II, the initial rapid drop in solution $\mathrm{pH}$ influenced the reaction rate in eq 5 and the speciation of $\mathrm{Dy}^{3+}$ in solution.

When the TiP_0:1 material was equilibrated in $0.1 \mathrm{M}$ $\mathrm{HNO}_{3}$, a negligible amount of Ti was detected in the solution, thereby excluding the dissolution-precipitation mechanism. $\mathrm{Ln}^{3+}$ complexes with dialkylphosphoric acids were determined to be in a polymeric arrangement, in which each $\mathrm{Ln}^{3+}$ center is surrounded by six oxygen atoms from the ligand in a pseudooctahedral environment. ${ }^{43}$ Given the above observations, the $\mathrm{Ln}^{3+}$ uptake on the TiP_0:1 sample is illustrated in Scheme 2. The selectivity arises from the preferential transmetalation reaction (framework cation exchange). Tasaki-Handa has systematically studied the $\mathrm{Ln}^{3+} / \mathrm{Ln}^{3+}$ ion-exchange behavior in the coordination polymers based on DEHPA. ${ }^{44,45}$ The ionexchange affinity was ascribed to coordination preference and steric strain. On the one hand, because of the Ln contraction, the coordination preference follows the reverse atomic number sequence in the $\mathrm{Ln}$ series. Smaller ions coordinate stronger with the DBP groups. On the other hand, the steric strain effect amplifies the same selectivity order. The ionic radius of $\mathrm{Ti}^{4+}(74.5 \mathrm{pm})$ is significantly smaller than that of $\mathrm{Ln}^{3+}$ (86.1$103.2 \mathrm{pm}$, six-coordinated). The non-isostructural insertion of larger $\mathrm{Ln}^{3+}$ ions into the TiP framework requires more energy because of the higher degree of structural distortion. The level of steric strain caused by the $\mathrm{TiO}^{2+} \leftrightarrow \mathrm{Ln}^{3+}$ exchange is expected to be even higher compared to that by the equivalent $\mathrm{Ln}^{3+} \leftrightarrow \mathrm{Ln}^{3+}$ exchange. Thus, we were able to obtain higher $\mathrm{SF}(\mathrm{Dy} / \mathrm{Nd})$ values compared with earlier studies using equivalent framework ion exchange ${ }^{46}$ and fraction precipitation by organophosphoric acids. ${ }^{10,26,27}$

To support the proposed mechanism, the $\mathrm{Dy}^{3+}$-loaded TiP_0:1 material (after equilibrating for $20 \mathrm{~d}$ in system II, denoted as TiP_0:1_Dy) was characterized and compared with pristine $\overline{\mathrm{TiP}} \overline{0}_{0} 1$ as well as the synthesized pure $\mathrm{Dy}(\mathrm{DBP})_{3}$ and/or $\overline{\mathrm{N}} \mathrm{d}(\mathrm{DBP})_{3}$ coordination polymers. Powder XRD patterns (Figure 5a) reveal the shrinkage of interlayer distance after $\mathrm{Dy}^{3+}$ exchange and structural distortion. Two peaks appeared for the TiP_0:1_Dy sample corresponding to $d$ spacings of 1.40 and $1.3 \overline{1} \mathrm{~nm}$. Dy $(\mathrm{DBP})_{3}$ crystallizes in a monoclinic fashion, ${ }^{26}$ and the peak $(d=1.29 \mathrm{~nm})$ here represents the distance between the chains. The ATR-FTIR spectra (Figure $5 \mathrm{~b}$ ) show a doublet at approximately 1170 and $1100 \mathrm{~cm}^{-1}$, supposedly because of the vibration of the $\mathrm{POO}^{-}$
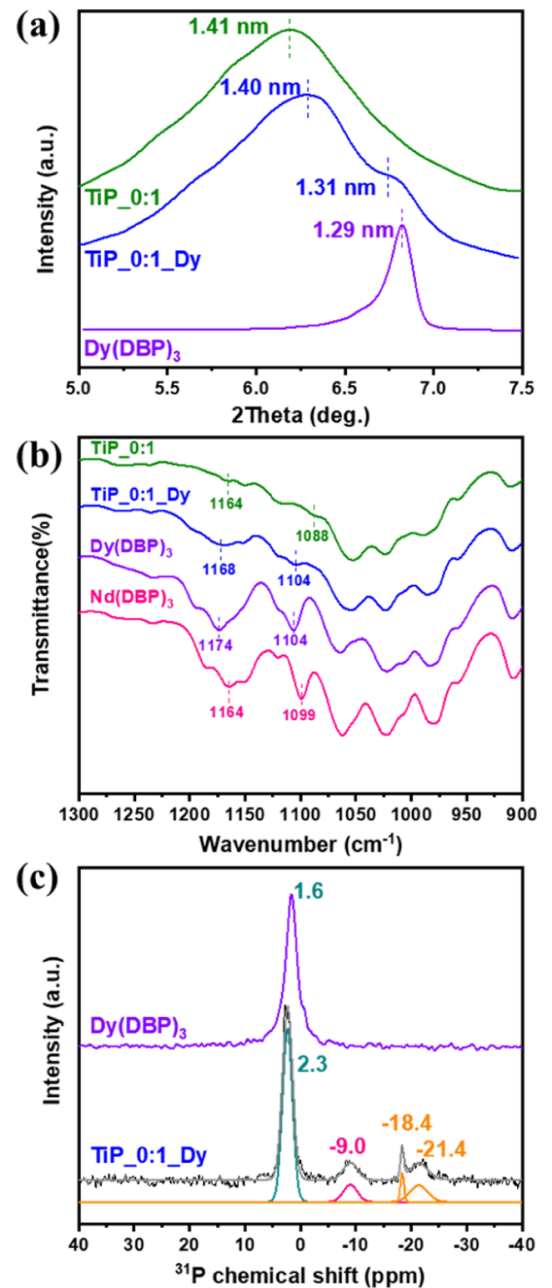

Figure 5. Characterizations of $\mathrm{Dy}^{3+}-$ loaded TiP_0:1 (TiP_0:1_Dy) compared with the original TiP_0:1 and/or synthesized $\overline{D y}(\overline{D B P})_{3}$ and $\mathrm{Nd}(\mathrm{DBP})_{3}$. (a) Powder $\mathrm{XRD}$ patterns in the $2 \theta$ range of $5.0-$ $7.5^{\circ}$. (b) ATR-FTIR spectra in the $900-1300 \mathrm{~cm}^{-1}$ range. (c) Solidstate ${ }^{31} \mathrm{P}$ MAS NMR spectrum with peak deconvolutions.

group. ${ }^{44}$ This exact doublet shifted toward the value of Dy $(\mathrm{DBP})_{3}$ in the TiP_0:1_Dy sample. The Raman and UVvis diffuse reflectance spectra were also checked before and after $\mathrm{Dy}^{3+}$ loading, yet no evident changes were found. Hydrolysis induced small amounts of $-\mathrm{H}_{2} \mathrm{PO}_{4}$ groups, as they were found by the ${ }^{31} \mathrm{P}$ NMR peaks with chemical shifts at -18.4 and $-21.4 \mathrm{ppm}$ in the TiP_0:1_Dy material (Figure 5c). Further studies in exploring the local coordination environment of the loaded $\mathrm{Ln}^{3+}$ are needed to fully justify our proposed mechanism.

Extraction from Dilute $\mathrm{Ln}^{3+}$ Mixtures. The ion-exchange uptake preference of $\mathrm{Ln}^{3+}$ on the TiP_0:1 material was tested 
under batch condition in a mixture consisting of $10 \mathrm{mg} \mathrm{L}^{-1}$ of all $\mathrm{Ln}^{3+}$ ions. Because of their chemical similarity, $\mathrm{Sc}^{3+}$ and $\mathrm{Y}^{3+}$ were also added to the mixture. The extraction appeared to be $\mathrm{pH}$-dependent, and the increase of equilibrium $\mathrm{pH}$ increased the uptake (Figure 6a). The $\mathrm{pH}$ dependency can be explained
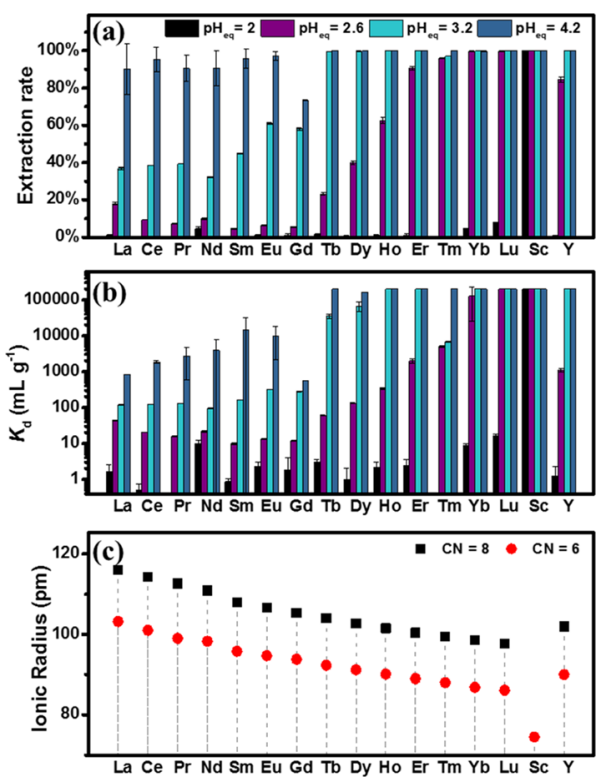

Figure 6. Extraction rates $(\mathrm{a})$ and distribution coefficients $\left(K_{\mathrm{d}}\right)$ values (b) for metal uptake on the TiP 0:1 material. The ionic radii of the tested elements with different coordination numbers are indicated in (c). ${ }^{3}$ Initial solution composition: $10 \mathrm{mg} \mathrm{L}^{-1}$ mixture of all $\mathrm{Ln}^{3+}$ (except radioactive $\mathrm{Pm}^{3+}$ ) together with $\mathrm{Sc}^{3+}$ and $\mathrm{Y}^{3+}$. The maximum $K_{\mathrm{d}}$ value in the study is presented as $199800 \mathrm{~mL} \mathrm{~g}^{-1}$, calculated from the detection limit $\left(10 \mu \mathrm{g} \mathrm{L}^{-1}\right)$.

by eqs 5 and $6 . \mathrm{Sc}^{3+}$, having the smallest ionic radius, was completely retained by the material even at $\mathrm{pHs}$ as low as 2.0 . The extraction efficiency and $K_{d}$ value for $\mathrm{Y}^{3+}$ lay between those for $\mathrm{Ho}^{3+}$ and $\mathrm{Er}^{3+}$, and this is concurrent with their ionic radii for six-coordinated ions: $90.1 \mathrm{pm}$ for $\mathrm{Ho}^{3+}, 90.0 \mathrm{pm}$ for $\mathrm{Y}^{3+}$, and $89.0 \mathrm{pm}$ for $\mathrm{Er}^{3+}$.

Across the Ln series, the extraction rate did not follow Ln contraction completely. Instead, the Ln "tetrad effect" was observed. ${ }^{47}$ The extraction rate showed discontinuities at the positions of $1 / 4$ filling (between $\mathrm{Nd}$ and $\mathrm{Pm}$ ) and half filling (Gd) of the $4 \mathrm{f}$ electron subshell. The discontinuity at $3 / 4$ filling (between Ho and Er) was not visible because of high extraction rates. This effect is commonly observed in the distribution of $\mathrm{Ln}$ in seawater and minerals, and it originates from the variations of interelectronic repulsion for the ground states across the Ln series. ${ }^{48}$ In terms of the distribution coefficients $\left(K_{\mathrm{d}}\right.$, Figure $\left.6 \mathrm{~b}\right)$, a clear dividing line can be drawn between Gd and Tb. The present study establishes that the group separation between early $\mathrm{Ln}(\mathrm{La}-\mathrm{Gd})$ and late $\mathrm{Ln}(\mathrm{Tb}-$ $\mathrm{Lu})$ could be effectively carried out on the TiP materials. The group $\mathrm{SFs}[\mathrm{SF}(\mathrm{Tb}-\mathrm{Lu} / \mathrm{La}-\mathrm{Gd})]$ were calculated as $2.0 \pm 0.3$, $28.7 \pm 0.4,203.1 \pm 3.4$, and $112.5 \pm 35.3$ at, respectively, $\mathrm{pH}$ 2.0, 2.6, 3.2, and 4.2.

Binary $\mathrm{Ln}^{3+}$ Separation Models. Binary $\mathrm{Ln}^{3+}$ uptake experiments were carried out to investigate in detail the potential separation behavior. Seven combinations were chosen across the $\mathrm{Ln}$ series: $\mathrm{La}-\mathrm{Ce}, \mathrm{Pr}-\mathrm{Nd}, \mathrm{Eu}-\mathrm{Gd}, \mathrm{Gd}-$ $\mathrm{Tb}, \mathrm{Tb}-\mathrm{Dy}, \mathrm{Yb}-\mathrm{Lu}$, and $\mathrm{Nd}-\mathrm{Dy}$. The uptake of $\mathrm{Ln}^{3+}$ by the
TiP 0:1 material from the $1 \mathrm{mM}$ equimolar binary mixture was monitored as a function of solution equilibrium $\mathrm{pH}$. Among these combinations, the first six represent adjacent $\mathrm{Ln}$ pairs, whereas the last one is a typical example for early and late Ln separation. The adjacent Ln pair $\mathrm{Gd}-\mathrm{Tb}$ was studied because their distribution coefficients signify a clear discontinuity in the earlier section.

Adjacent Ln pairs are known to share extremely similar chemical properties, and their separation is one of the most difficult tasks in inorganic separations. The similarities of the adjacent Ln pairs are observed based on the almost identical shape of their $K_{\mathrm{d}}$ versus $\mathrm{pH}_{\mathrm{eq}}$ curves (in Figures S8-S13, Supporting Information). The uptake preference (represented by the SFs, Figure $7 \mathrm{a}-\mathrm{f}$ ) in the current case strictly followed

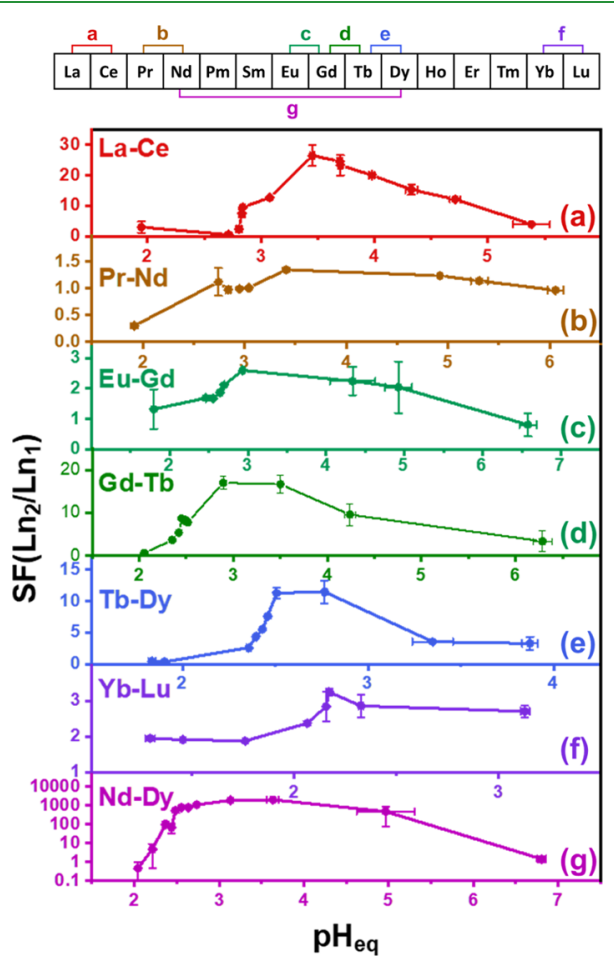

Figure 7. SFs between selected $\mathrm{Ln}^{3+}$ pairs [(a) La-Ce; (b) $\mathrm{Pr}-\mathrm{Nd}$; (c) Eu-Gd; (d) Gd-Tb; (e) Tb-Dy; (f) Yb-Lu; and (g) Nd-Dy] as a function of solution $\mathrm{pH}$. Initial solution composition: $1 \mathrm{mM}$ equimolar mixture of the selected $\mathrm{Ln}^{3+}$ pair. The corresponding $K_{\mathrm{d}}$ values are available in Figure S8-S14 in the Supporting Information.

the reversed $\mathrm{Ln}$ contraction order $\left(\mathrm{Lu}^{3+} \rightarrow \mathrm{La}^{3+}\right)$, whereby $\mathrm{Ln}^{3+}$ ions with smaller radii were preferentially retained. This deviates from the Ln tetrad effect. We suggest that the tetrad effect only becomes evident if the concentrations of $\mathrm{Ln}$ are relatively low. If there are large amounts of competing $\mathrm{Ln}^{3+}$ ions, the coordination and steric strain preferences favor the smaller $\mathrm{Ln}^{3+}$. The separation between $\mathrm{Gd}$ and $\mathrm{Tb}$ is significantly easier compared to that between $\mathrm{Eu}$ and $\mathrm{Gd}$, although both pairs are adjacent $\mathrm{Ln}$. These results confirm the group separation behavior that $\mathrm{Ln}$ series is divided into two subgroups: from $\mathrm{La}$ to $\mathrm{Gd}$ as early $\mathrm{Ln}$ and from $\mathrm{Tb}$ to $\mathrm{Lu}$ as late $\mathrm{Ln}$ in our current work. In addition, significant $\mathrm{Nd}-\mathrm{Dy}$ separation was achieved (Figures $7 \mathrm{~g}$ and S14), possibly because of their larger differences in ionic radii.

The sole external parameter contributing to the separations is the equilibrium $\mathrm{pH}$ of the solution in our proposed system. This means that, through delicate control over the solution $\mathrm{pH}$, 
optimal separations can be achieved either by leaving the majority of the larger $\mathrm{Ln}^{3+}$ in the solution or by exchanging the majority of the smaller $\mathrm{Ln}^{3+}$ onto the TiP material. The optimal molar fractions (best values obtained from the binary competitive batch systems) of the $\mathrm{Ln}$ in the liquid and solid phases are plotted in Figure 8a. Through only one uptake

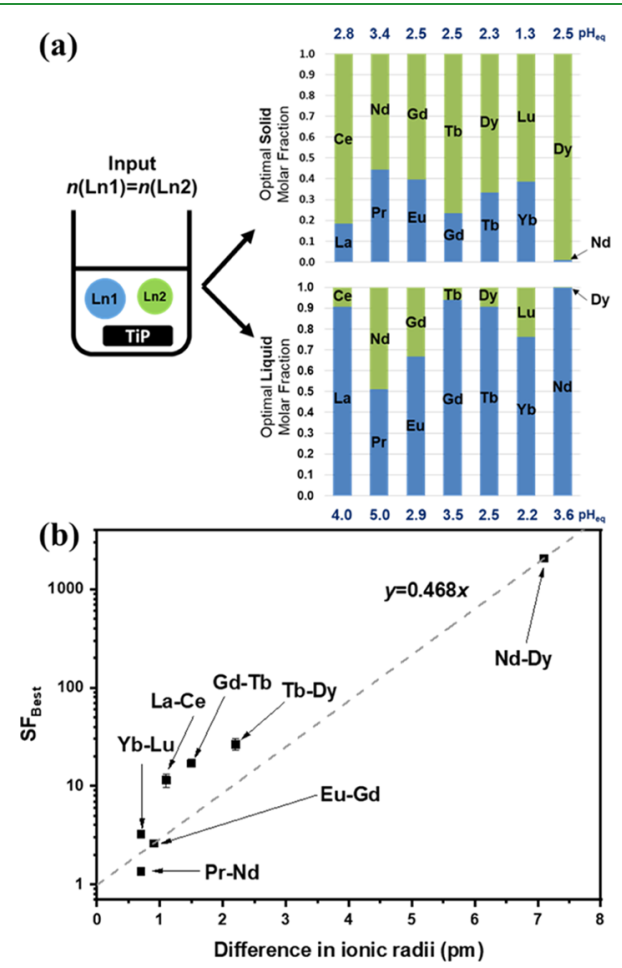

Figure 8. (a) Stacked column plots showing the optimal Ln fractions in the solid and the liquid phases obtained from the binary uptake study at different equilibrium $\mathrm{pH}$ values. (b) Dependence of the best achieved SFs using a logarithmic scale on the ionic radii difference of the $\mathrm{Ln}^{3+}$ pairs.

cycle, the heavier Ln in the adjacent Ln pairs was concentrated in the solid phase, representing some $60-80 \%$ of the total $\mathrm{Ln}$ fraction. Concurrently, the lighter Ln was concentrated in the liquid phase. The separation of $\mathrm{Nd}$ and Pr remained the most difficult one. Notably, almost complete Nd-Dy separation was achieved batchwise, as more than $99 \%$ of the loaded Ln was Dy.

Because the separation capability originates from the small differences in ionic radii, we plotted the best achieved SFs (on a logarithmic scale) versus the differences in ionic radii (Figure $8 b) . \mathrm{Ln}^{3+}$ forms an $\operatorname{Ln}(\mathrm{DBP})_{3}$ complex; therefore, the ionic radii of six-coordinated ions were used. The linear regression line was drawn, and it appears that a larger difference in the ionic radii is positively correlated with the separation behavior. Overall, these results emphasize the potential technological significance of the TiP materials in Ln separation.

Transmetalation as a Metal Separation Process. Transmetalation is a type of organometallic reaction during which the organic ligands are transferred from one metal ion to another. It has been shown in recent years that MOFs and coordination polymers are applicable hosts for transmetalation. Partial, core-shell, complete, or even single-crystal-to-singlecrystal metal exchanges were reported. ${ }^{49}$ The metal exchange depends on ionic radii differences, preferential coordination geometries, kinetics, framework flexibility, and solvent effects. ${ }^{50}$
It appears that transmetalation on water-stable MOFs and coordination polymers is worth exploring as a hydrometallurgical metal separation approach. The effects of codissolving metal ions $\left(\mathrm{Fe}^{3+}, \mathrm{Al}^{3+}, \mathrm{Ca}^{2+}\right.$, etc. $)$ in real samples need to be taken into consideration when further assessing the performance of the process. However, the intralanthanide separation is still preferably to be placed as a downstream process when all other metal ions, except for $\mathrm{Ln}^{3+}$, are eliminated.

Comparison with Literature Results. Table 4 summarizes some intralanthanide separation approaches reported in

Table 4. Intralanthanide Separation Capability Comparisons with Literature Reported Approaches

\begin{tabular}{|c|c|c|c|c|}
\hline classification & method/reagent & $\begin{array}{l}\text { target Ln } \\
\text { pair }\end{array}$ & SF & references \\
\hline \multirow{2}{*}{$\begin{array}{l}\text { solvent } \\
\text { extraction }\end{array}$} & DEHPA & $\mathrm{Nd}-\mathrm{Dy}$ & 12.93 & 51 \\
\hline & Cyanex 923 & Nd-Dy & 12.79 & 51 \\
\hline $\begin{array}{l}\text { solvent } \\
\text { leaching }\end{array}$ & tripodal nitroxide ligand & Nd-Dy & 359 & 52 \\
\hline \multirow[t]{3}{*}{ crystallization } & HDBP & Nd-Dy & $>300$ & 26 \\
\hline & borate & $\mathrm{Nd}-\mathrm{Dy}$ & 986 & 8 \\
\hline & camphorate & $\mathrm{Tb}-\mathrm{Dy}$ & 1.247 & 15 \\
\hline \multirow[t]{6}{*}{ ion exchange } & $\begin{array}{l}\text { amorphous zirconium } \\
\text { phosphate }\end{array}$ & Nd-Dy & 1.9 & 25 \\
\hline & $\mathrm{Ce}(\mathrm{DEHP})_{3}$ & $\mathrm{La}-\mathrm{Dy}$ & 1.6 & 46 \\
\hline & $\mathrm{Fe}(\mathrm{DEHP})_{3}$ & La-Dy & 18.4 & 46 \\
\hline & $\mathrm{Al}(\mathrm{DEHP})_{3}$ & $\mathrm{La}-\mathrm{Dy}$ & 3.5 & 46 \\
\hline & $\begin{array}{l}\text { titanium(IV)butyl } \\
\text { phosphate }\end{array}$ & $\mathrm{Nd}-\mathrm{Dy}$ & 2065 & this work \\
\hline & & $\mathrm{Tb}-\mathrm{Dy}$ & 11.5 & this work \\
\hline
\end{tabular}

recent years, with an emphasis on solvent extraction, ${ }^{51}$ solvent leaching, ${ }^{52}$ crystallization, ${ }^{8,15,26}$ and ion-exchange methods. ${ }^{25,46}$ Organic phosphorus-containing ligands are in general selective for Ln separation. Our method appears to be the best in terms of SF, though this is far from the sole judgmental factor for a successful separation process. Titanium(IV) serves as sacrificial ion-exchange sites, and the dissolved $\mathrm{TiO}^{2+}$ hydrolyzes into hydroxides. In reality, the complete regeneration of the material might not be possible because of the formation of titanate phases. Additionally, organophosphates can be attacked by $\mathrm{H}^{+}$, hydrolyzing into inorganic phosphate and alcohol. Finding a reasonable compromising point between selectivity and operational ease marks out our road ahead. The ultimate goal is a solvent-free, efficient, recyclable, and selective method that requires neither toxic chemicals nor intensive energy input.

\section{CONCLUSIONS}

We have demonstrated the basis of a Ln separation strategy utilizing a transmetalation reaction on layered titanium(IV) organophosphate materials, as opposed to the extraframework ion-exchange materials. These coordination polymers were easily prepared by a precipitation reaction and showed potential in intralanthanide separation, especially for the separation between early and late $\mathrm{Ln}$. The selective Ln uptake was controlled by solution $\mathrm{pH}$ and did not require any additional energy input (e.g., hydrothermal condition). The selectivity arose from the ligand coordination and steric strain preferences during the transmetalation reaction and structural distortion. The separation performance of the transmetalation 
reaction seems higher compared to the selective crystallization or solvent extraction process utilizing the same or a similar organophosphate ligand. That said, the stability of the material as well as the regeneration needs to be further studied to warrant the design of a true separation process. Through alterations of the framework metal (size and valence) and organophosphate ligand, a variety of new MOF or coordination polymer materials can be envisioned with enhanced and tunable metal selectivity in aqueous solutions.

\section{ASSOCIATED CONTENT}

\section{S Supporting Information}

The Supporting Information is available free of charge on the ACS Publications website at DOI: 10.1021/acsami.8b04480.

Formula calculation for TiPs, SEM images of the pyrophosphates, preliminary Ln uptake results, kinetic modeling, and $K_{\mathrm{d}}$ versus $\mathrm{pH}$ plots for binary $\mathrm{Ln}^{3+}$ extraction study (PDF)

\section{AUTHOR INFORMATION}

\section{Corresponding Author}

*E-mail: Wenzhong.Zhang@helsinki.fi.

ORCID $\odot$

Wenzhong Zhang: 0000-0001-9184-0723

Sami Hietala: 0000-0003-1448-1813

Leonid Khriachtchev: 0000-0002-1146-5212

Timo Hatanpää: 0000-0003-3745-8296

Bhairavi Doshi: 0000-0002-8355-533X

Risto Koivula: 0000-0002-6547-9775

Notes

The authors declare no competing financial interest.

\section{ACKNOWLEDGMENTS}

The research leading to these results has received funding from the European Community's Horizon 2020 Program under grant agreement no. 636876 (MSCA-ETN REDMUD). This paper reflects only the authors' view, exempting the Community from any liability. Project website: http://etn. redmud.org/. W.Z. thanks Dženita Avdibegović (KU Leuven) for inspiring discussion and ICP-OES analysis and Karina Moslova (University of Helsinki) for CHN EA. The authors would like to dedicate this article in memoriam to Professor Risto Harjula (1956-2017), a pioneer in science, a beloved teacher, and a kind friend.

\section{REFERENCES}

(1) Bünzli, J.-C. G. Benefiting from the Unique Properties of Lanthanide Ions. Acc. Chem. Res. 2006, 39, 53-61.

(2) Binnemans, K. Lanthanide-Based Luminescent Hybrid Materials. Chem. Rev. 2009, 109, 4283-4374.

(3) Shannon, R. D. Revised Effective Ionic Radii and Systematic Studies of Interatomic Distances in Halides and Chalcogenides. Acta Crystallogr., Sect. A: Cryst. Phys., Diffr., Theor. Gen. Crystallogr. 1976, 32, $751-767$.

(4) Kanazawa, Y.; Kamitani, M. Rare Earth Minerals and Resources in the World. J. Alloys Compd. 2006, 408-412, 1339-1343.

(5) Cotton, S. Lanthanide and Actinide Chemistry; John Wiley \& Sons, 2013.

(6) Lucy, C. A. Evolution of Ion-Exchange: from Moses to the Manhattan Project to Modern Times. J. Chromatogr. A 2003, 1000, $711-724$.
(7) Sun, X.; Luo, H.; Dai, S. Ionic Liquids-Based Extraction: A Promising Strategy for the Advanced Nuclear Fuel Cycle. Chem. Rev. 2011, 112, 2100-2128.

(8) Yin, X.; Wang, Y.; Bai, X.; Wang, Y.; Chen, L.; Xiao, C.; Diwu, J.; Du, S.; Chai, Z.; Albrecht-Schmitt, T. E.; Wang, S. Rare Earth Separations by Selective Borate Crystallization. Nat. Commun. 2017, 8,14438 .

(9) Hatanaka, T.; Matsugami, A.; Nonaka, T.; Takagi, H.; Hayashi, F.; Tani, T.; Ishida, N. Rationally Designed Mineralization for Selective Recovery of the Rare Earth Elements. Nat. Commun. 2017, 8,15670 .

(10) Tasaki-Handa, Y.; Abe, Y.; Ooi, K.; Narita, H.; Tanaka, M.; Wakisaka, A. Separation of Neodymium and Dysprosium by Forming Coordination Polymers. Sep. Purif. Technol. 2016, 157, 162-168.

(11) Gao, H. Y.; Peng, W. L.; Meng, P. P.; Feng, X. F.; Li, J. Q.; Wu, H. Q.; Yan, C. S.; Xiong, Y. Y.; Luo, F. Lanthanide Separation Using Size-Selective Crystallization of Ln-MOFs. Chem. Commun. 2017, 53, 5737-5739.

(12) Wang, Y.; Lu, H.; Dai, X.; Duan, T.; Bai, X.; Cai, Y.; Yin, X.; Chen, L.; Diwu, J.; Du, S.; Zhou, R.; Chai, Z.; Albrecht-Schmitt, T. E.; Liu, N.; Wang, S. Facile and Efficient Decontamination of Thorium from Rare Earths Based on Selective Selenite Crystallization. Inorg. Chem. 2018, 57, 1880-1887.

(13) Wang, Y.; Duan, T.; Weng, Z.; Ling, J.; Yin, X.; Chen, L.; Sheng, D.; Diwu, J.; Chai, Z.; Liu, N.; Wang, S. Mild Periodic Acid Flux and Hydrothermal Methods for the Synthesis of Crystalline fElement-Bearing Iodate Compounds. Inorg. Chem. 2017, 56, 1304113050 .

(14) Li, X.-Z.; Zhou, L.-P.; Yan, L.-L.; Dong, Y.-M.; Bai, Z.-L.; Sun, X.-Q.; Diwu, J.; Wang, S.; Bünzli, J.-C.; Sun, Q.-F. A Supramolecular Lanthanide Separation Approach Based on Multivalent Cooperative Enhancement of Metal Ion Selectivity. Nat. Commun. 2018, 9, 547.

(15) Zhao, X.; Wong, M.; Mao, C.; Trieu, T. X.; Zhang, J.; Feng, P.; $\mathrm{Bu}, \mathrm{X}$. Size-Selective Crystallization of Homochiral Camphorate Metal-Organic Frameworks for Lanthanide Separation. J. Am. Chem. Soc. 2014, 136, 12572-12575.

(16) Florek, J.; Giret, S.; Juère, E.; Larivière, D.; Kleitz, F. Functionalization of Mesoporous Materials for Lanthanide and Actinide Extraction. Dalton Trans. 2016, 45, 14832-14854.

(17) Silbernagel, R.; Martin, C. H.; Clearfield, A. Zirconium(IV) Phosphonate-Phosphates as Efficient Ion-Exchange Materials. Inorg. Chem. 2016, 55, 1651-1656.

(18) Shusterman, J. A.; Mason, H. E.; Bowers, J.; Bruchet, A.; Uribe, E. C.; Kersting, A. B.; Nitsche, H. Development and Testing of Diglycolamide Functionalized Mesoporous Silica for Sorption of Trivalent Actinides and Lanthanides. ACS Appl. Mater. Interfaces 2015, 7, 20591-20599.

(19) Florek, J.; Chalifour, F.; Bilodeau, F.; Larivière, D.; Kleitz, F. Nanostructured Hybrid Materials for the Selective Recovery and Enrichment of Rare Earth Elements. Adv. Funct. Mater. 2014, 24, $2668-2676$.

(20) Zheng, X.; Zhang, F.; Liu, E.; Xu, X.; Yan, Y. Efficient Recovery of Neodymium in Acidic System by Free-Standing Dual-Template Docking Oriented Ionic Imprinted Mesoporous Films. ACS Appl. Mater. Interfaces 2017, 9, 730-739.

(21) Zhang, W.; Avdibegović, D.; Koivula, R.; Hatanpää, T.; Hietala, S.; Regadío, M.; Binnemans, K.; Harjula, R. Titanium Alkylphosphate Functionalised Mesoporous Silica for Enhanced Uptake of Rare-Earth Ions. J. Mater. Chem. A 2017, 5, 23805-23814.

(22) Clearfield, A. Role of Ion Exchange in Solid-State Chemistry. Chem. Rev. 1988, 88, 125-148.

(23) Silbernagel, R.; Shehee, T. C.; Martin, C. H.; Hobbs, D. T.; Clearfield, A. $\mathrm{Zr} / \mathrm{Sn}$ (IV) Phosphonates as Radiolytically Stable IonExchange Materials. Chem. Mater. 2016, 28, 2254-2259.

(24) Zhang, W.; Koivula, R.; Wiikinkoski, E.; Xu, J.; Hietala, S.; Lehto, J.; Harjula, R. Efficient and Selective Recovery of Trace Scandium by Inorganic Titanium Phosphate Ion-Exchangers from Leachates of Waste Bauxite Residue. ACS Sustainable Chem. Eng. 2017, 5, 3103-3114. 
(25) Xu, J.; Koivula, R.; Zhang, W.; Wiikinkoski, E.; Hietala, S.; Harjula, R. Separation of Cobalt, Neodymium and Dysprosium Using Amorphous Zirconium Phosphate. Hydrometallurgy 2018, 175, 170178.

(26) Tasaki-Handa, Y.; Abe, Y.; Ooi, K.; Narita, H.; Tanaka, M.; Wakisaka, A. Selective Crystallization of Phosphoester Coordination Polymer for the Separation of Neodymium and Dysprosium: A Thermodynamic Approach. J. Phys. Chem. B 2016, 120, 1273012735.

(27) Tasaki-Handa, Y.; Abe, Y.; Ooi, K.; Narita, H.; Tanaka, M.; Wakisaka, A. Environmentally Friendly Separation of Dysprosium and Neodymium by Fractional Precipitation of Coordination Polymers. RSC Adv. 2014, 4, 20496-20498.

(28) Peppard, D. F.; Mason, G. W.; Maier, J. L.; Driscoll, W. J. Fractional Extraction of the Lanthanides as Their Di-Alkyl Orthophosphates. J. Inorg. Nucl. Chem. 1957, 4, 334-343.

(29) Tanaka, H.; Ishida, K.; Okumiya, T.; Murakami, M. Preparation and Exfoliation of Layered Titanium Butyl Phosphates. Colloid Polym. Sci. 2010, 288, 1427-1433.

(30) Ma, T.-Y.; Zhang, X.-J.; Shao, G.-S.; Cao, J.-L.; Yuan, Z.-Y. Ordered Macroporous Titanium Phosphonate Materials: Synthesis, Photocatalytic Activity, and Heavy Metal Ion Adsorption. J. Phys. Chem. C 2008, 112, 3090-3096.

(31) Zheng, T.; Yang, Z.; Gui, D.; Liu, Z.; Wang, X.; Dai, X.; Liu, S.; Zhang, L.; Gao, Y.; Chen, L.; Sheng, D.; Wang, Y.; Diwu, J.; Wang, J.; Zhou, R.; Chai, Z.; Albrecht-Schmitt, T. E.; Wang, S. Overcoming the Crystallization and Designability Issues in the Ultrastable Zirconium Phosphonate Framework System. Nat. Commun. 2017, 8, 15369.

(32) Assi, H.; Mouchaham, G.; Steunou, N.; Devic, T.; Serre, C. Titanium Coordination Compounds: From Discrete Metal Complexes to Metal-Organic Frameworks. Chem. Soc. Rev. 2017, 46, $3431-3452$.

(33) Trublet, M.; Rusanova, D.; Antzutkin, O. N. Revisiting Syntheses of $\mathrm{Ti}(\mathrm{IV}) / \mathrm{H}_{2} \mathrm{PO}_{4}-\mathrm{HPO}_{4}$ Functional Ion-Exchangers, Properties and Features. New J. Chem. 2018, 42, 838-845.

(34) Low, J. J.; Benin, A. I.; Jakubczak, P.; Abrahamian, J. F.; Faheem, S. A.; Willis, R. R. Virtual High Throughput Screening Confirmed Experimentally: Porous Coordination Polymer Hydration. J. Am. Chem. Soc. 2009, 131, 15834-15842.

(35) Gillens, A. R.; Powell, B. A. A Novel Technique for the Rapid Determination of Tributyl Phosphate Degradation From Alkaline Hydrolysis in Aqueous and Organic Phases Using FTIR-ATR and Verification of This Technique by Gas Chromatography. J. Radioanal. Nucl. Chem. 2016, 307, 1891-1899.

(36) Zhao, Y.; Zhu, G.; Jiao, X.; Liu, W.; Pang, W. Template Synthesis and Characterization of A New 2-D Layered Titanium Phosphate. J. Mater. Chem. 2000, 10, 463-467.

(37) Sakka, S.; Miyaji, F.; Fukumi, K. Structure of Binary $\mathrm{K}_{2} \mathrm{O}-\mathrm{TiO}_{2}$ and $\mathrm{Cs}_{2} \mathrm{O}-\mathrm{TiO}_{2}$ Glasses. J. Non-Cryst. Solids 1989, 112, 64-68.

(38) Schmutz, C.; Barboux, P.; Ribot, F.; Taulelle, F.; Verdaguer, M.; Fernandez-Lorenzo, C. EXAFS, Raman and 31P NMR study of amorphous titanium phosphates. J. Non-Cryst. Solids 1994, 170, 250262.

(39) Thommes, M.; Kaneko, K.; Neimark, A. V.; Olivier, J. P.; Rodriguez-Reinoso, F.; Rouquerol, J.; Sing, K. S. W. Physisorption of Gases, With Special Reference to the Evaluation of Surface Area and Pore Size Distribution (IUPAC Technical Report). Pure Appl. Chem. 2015, 87, 1051.

(40) Yin, H.; Wada, Y.; Kitamura, T.; Kambe, S.; Murasawa, S.; Mori, H.; Sakata, T.; Yanagida, S. Hydrothermal Synthesis of Nanosized Anatase and Rutile $\mathrm{TiO}_{2}$ Using Amorphous Phase $\mathrm{TiO}_{2}$. J. Mater. Chem. 2001, 11, 1694-1703.

(41) Islam, F.; Rahman, H.; Ali, M. Solvent Extraction Separation Study of $\mathrm{Ti}(\mathrm{IV}), \mathrm{Fe}(\mathrm{III})$ and $\mathrm{Fe}(\mathrm{II})$ From Aqueous Solutions with Di2-Ethyl Hexyl Phosphoric Acid in Benzene. J. Inorg. Nucl. Chem. 1979, 41, 217-221.

(42) Biswas, R. K.; Begum, D. A. Solvent Extraction of Tetravalent Titanium From Chloride Solution by Di-2-Ethylhexyl Phosphoric Acid in Kerosene. Hydrometallurgy 1998, 49, 263-274.
(43) Lumetta, G. J.; Sinkov, S. I.; Krause, J. A.; Sweet, L. E. Neodymium(III) Complexes of Dialkylphosphoric and Dialkylphosphonic Acids Relevant to Liquid-Liquid Extraction Systems. Inorg. Chem. 2016, 55, 1633-1641.

(44) Tasaki-Handa, Y.; Abe, Y.; Ooi, K.; Tanaka, M.; Wakisaka, A. Central Metal Ion Exchange in a Coordination Polymer Based on Lanthanide Ions and Di(2-Ethylhexyl)Phosphoric Acid: Exchange Rate and Tunable Affinity. J. Colloid Interface Sci. 2014, 413, 65-70.

(45) Tasaki-Handa, Y.; Abe, Y.; Ooi, K.; Tanaka, M.; Wakisaka, A. Steric Effect Involved in $\mathrm{Ln}^{3+} / \mathrm{Ce}^{3+}$ Exchange in A Coordination Polymer Based on Di(2-Ethylhexyl)Phosphoric Acid. Dalton Trans. 2014, 43, 1791-1796.

(46) Ooi, K.; Tasaki-Handa, Y.; Abe, Y.; Wakisaka, A. Lanthanide Ion Exchange Properties of A Coordination Polymer Consisting of $\mathrm{Di}\left(2\right.$-Ethylhexyl) Phosphoric Acid and Trivalent Metal Ions $\left(\mathrm{Ce}^{3+}\right.$, $\mathrm{Fe}^{3+}$, or $\mathrm{Al}^{3+}$ ). Dalton Trans. 2014, 43, 4807-4812.

(47) Peppard, D. F.; Mason, G. W.; Lewey, S. A Tetrad Effect in the Liquid-Liquid Extraction Ordering of Lanthanides(III). J. Inorg. Nucl. Chem. 1969, 31, 2271-2272.

(48) Nugent, L. J. Theory of the Tetrad Effect in the Lanthanide(III) and Actinide(III) Series. J. Inorg. Nucl. Chem. 1970, 32, 34853491.

(49) Das, S.; Kim, H.; Kim, K. Metathesis in Single Crystal: Complete and Reversible Exchange of Metal Ions Constituting the Frameworks of Metal-Organic Frameworks. J. Am. Chem. Soc. 2009, $131,3814-3815$.

(50) Lalonde, M.; Bury, W.; Karagiaridi, O.; Brown, Z.; Hupp, J. T.; Farha, O. K. Transmetalation: Routes to Metal Exchange Within Metal-Organic Frameworks. J. Mater. Chem. A 2013, 1, 5453-5468.

(51) Riaño, S.; Petranikova, M.; Onghena, B.; Vander Hoogerstraete, T.; Banerjee, D.; Foreman, M. R. S. J.; Ekberg, C.; Binnemans, K. Separation of Rare Earths and Other Valuable Metals From DeepEutectic Solvents: A New Alternative for the Recycling of Used NdFeB Magnets. RSC Adv. 2017, 7, 32100-32113.

(52) Bogart, J. A.; Lippincott, C. A.; Carroll, P. J.; Schelter, E. J. An Operationally Simple Method for Separating the Rare-Earth Elements Neodymium and Dysprosium. Angew. Chem., Int. Ed. 2015, 54, 82228225 . 